\title{
Viscoelastic Behaviour Characterization of a Gap-graded Asphalt Mixture with SBS Polymer Modified Bitumen
}

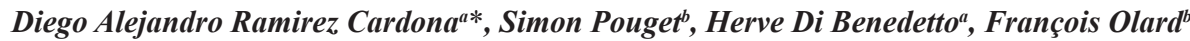 \\ ${ }^{a}$ Laboratoire Génie Civil et Bâtiment and Laboratory of Tribology and System Dynamics - LTDS \\ (UMR CNRS 5513), Ecole Nationale des Travaux Publics de l'Etat-ENTPE, \\ University of Lyon, (FR) 69518 Vaulx en Velin, Lyon, France \\ ${ }^{b}$ Research and Development Division, EIFFAGE Travaux Publics, (FR) 69960 Corbas, France
}

Received: October 27, 2014; Revised: April 5, 2015

\begin{abstract}
A characterization of the linear thermo-viscoelastic behaviour of a gap-graded bituminous mixture with SBS-polymer modified bitumen and RAP aggregates is presented in this paper. A comparison was made, in terms of their viscoelastic behaviour, between this innovative mixture and two commonly used well-graded base-course French mixtures made with pure bitumen. The materials were also compared in terms of viscous dissipated energy. Complex modulus tests on cylindrical samples were performed for each mixture. The viscoelastic behaviour of the materials was modelled using the 2S2P1D (2 springs, 2 parabolic elements, 1 dashpot) constitutive model which was developed in the Laboratory of Civil Engineering and Construction (LGCB) of the ENTPE, University of Lyon. The tests results allowed validating the time-temperature superposition principle for the studied mixtures. Experimental and modelled complex modulus $\left(\left|E^{*}\right|\right)$ master curves were built for each material. The gap-graded mixture was found to present higher stiffness values at low frequency/high temperature conditions, lower viscous behaviour and lower values of viscous dissipated energy compared to the conventional mixtures. Complex modulus tests were also carried out on the polymer modified bitumen of the gap-graded mixture. A link between the viscoelastic behaviour of both binder and mixture could be established thanks to the SHStS transformation developed by the ENTPE team.
\end{abstract}

Keywords: bituminous mixture, viscoelastic behaviour, thermo-mechanical properties, gap-graded mixture, complex modulus test, viscoelastic constitutive model, linear viscoelasticity

\section{Introduction}

Road transportation is experiencing a constant increase in traffic intensities. The higher traffic loads and circulation speeds and the ever increasing number of vehicles imply the need for road building materials with better mechanical performances and longer life expectancy. Parallel to this, the actual environmental context calls for a reduction of raw construction materials use. An innovative base-course mixture was conceived as a solution to the challenge of improving the properties of bituminous mixtures while reducing the use of raw aggregates and new bitumen. The formulation of this mixture, called GB5 $5^{\circledR}$, takes into account two important aspects: first; the optimization of the aggregate packing for higher stiffness ${ }^{1,2}$; and second, the use of SBS-polymer modified bitumen for reducing fatigue cracking and ageing ${ }^{3-7}$. Coupling both techniques would allow creating a sufficiently stiff and fatigue resistant material. In addition, the formulation includes a moderate to high percentage of reclaimed asphalt pavement (RAP) in order to cope with the environmental requirements. This paper focuses on the characterisation of the linear viscoelastic (LVE) behaviour of such a bituminous mixture in order to verify its mechanical performances and its advantages compared to conventional base-course mixtures.

*e-mail: diego.ramirezcardona@entpe.fr
Bituminous materials are known to have a complex mechanical behaviour ${ }^{8-11}$. As shown on Figure 1, bituminous materials present a linear viscoelastic (LVE) behaviour within the small strain domain $(\varepsilon<100 \mu \mathrm{m} / \mathrm{m})$ which can be fully defined by means of the complex modulus $\left(\mathrm{E}^{*}\right)$ and the complex Poisson's ratio $\left(v^{*}\right)^{12}$. The characterisation of the complex modulus presented in this paper was made on a large frequency and temperature domain by means of a mechanical tension-compression test on cylindrical samples. The complex modulus has been identified as a main parameter for calculating the response of a bituminous structure to traffic loading as well as its resistance to rutting and fatigue ${ }^{13}$.

In addition, the link between the rheological behaviour of the GB5 ${ }^{\circledR}$ mixture and its binder is studied. The SHStS transformation developed at the ENTPE ${ }^{14-17}$ was used and validated. It allows predicting the complex modulus of the mixture from the complex modulus of the binder (and vice versa).

\section{Linear Viscoelasticity}

Figure 1 presents the different types of behaviour observed for bituminous mixtures according to the amplitude of the applied strain and the quantity of loading cycles. Within the small strain domain $(\varepsilon<100 \mu \mathrm{m} / \mathrm{m})$ and for limited number of 
cycles, bituminous materials present a LVE behaviour ${ }^{8,9}$. This means that the material's response to a number of elementary loadings is the addition of each of the elementary responses ${ }^{10}$.

The stress response of linear viscoelastic materials to any strain loading can be expressed using the relaxation function $(\mathrm{R}(\mathrm{t})$ ) (Equation 1). Applying the Carson transformation (Equation 2), the $\mathrm{R}$ function can be transformed to an expression similar to an elastic law (Equation 3$)^{10}$.

$$
\begin{aligned}
& \sigma(t)=\int_{0}^{t} R(t-\tau) d \varepsilon(\tau) \\
& \tilde{f}(p)=\int_{0}^{\infty} p e^{-p t} f(t) d t \\
& \tilde{\sigma}(p)=\tilde{R}(p) \cdot \tilde{\varepsilon}(p)
\end{aligned}
$$

Where $p$ is a complex number. For a sinusoidal loading, given the viscous properties of bituminous mixtures, there exists a phase lag $(\varphi)$ between stress and strain. Equations 4 and 5 express strain $\varepsilon$ and stress $\sigma$ for this type of loading, where $\varepsilon_{01}$ and $\sigma_{01}$ are the strain and stress amplitudes and $\omega$ the pulsation $(\omega=2 \pi f$, where $f$ is the frequency). The subscript 1 means axial direction for the performed test conditions, which are presented in the next section. Figure 2, presents an example of the obtained stress and strain signals from the complex modulus test on the gap-graded mixture.

$$
\begin{aligned}
& \varepsilon_{1}(t)=\varepsilon_{01} \sin (\omega t) \\
& \sigma_{1}(t)=\sigma_{01} \sin (\omega t+\varphi)
\end{aligned}
$$

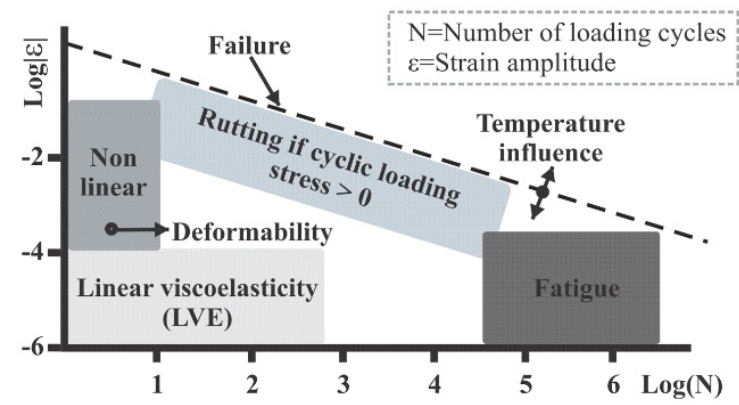

Figure 1. Domains of behaviour for bituminous mixtures ${ }^{10}$.

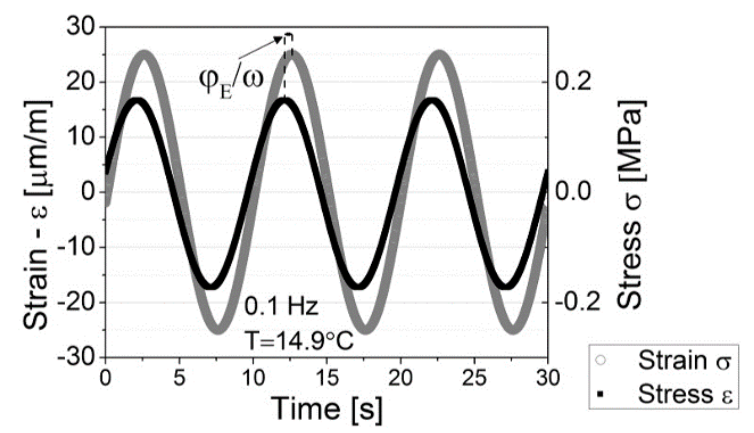

Figure 2. Example of stress and strain signals - Complex modulus test on the $\mathrm{GB} 5^{\circledR}$ mixture (gap-graded) $\left(\mathrm{f}=0.1 \mathrm{~Hz}\right.$ and $\left.\mathrm{T}=14.9^{\circ} \mathrm{C}\right)$.
Introducing a complex number $\mathrm{j}$ defined by $\mathrm{j}^{2}=-1$, Equations 4 and 5 can be rewritten and placed in Equation 3 as presented in Equation 6. The complex modulus is classically described from the results of sinusoidal loading tests as it corresponds to the value of the Carson transform of the relaxation function () at a point " $\mathrm{j \omega} \omega$ " (Equation 6) ${ }^{10}$. The evolution of the complex modulus with frequency and temperature gives the complete LVE characterisation of the material ${ }^{18}$.

$E^{*}=\tilde{R}(j \omega)=\frac{\sigma_{01}}{\varepsilon_{01}} e^{j \varphi}=\left|E^{*}\right| e^{j \varphi}$

$E^{*}$ depends on the loading frequency as well as the temperature $^{10}$. The Time-Temperature Superposition Principle (TTSP) stands that a unique reduced variable, the equivalent frequency $\mathrm{f}_{\text {eq, }}$ can be introduced to describe the evolution of the complex modulus for every frequency/temperature loading condition (Equation 7). Hence, a same complex modulus norm $\left(\left|E^{*}\right|\right)$ value can be obtained at different combinations of loading frequency $\omega$ and temperature $\mathrm{T}$, as long as $\omega_{1} f\left(\mathrm{~T}_{1}\right)=\omega_{2} f\left(\mathrm{~T}_{2}\right)$. Considering a complex modulus test including various temperatures $\left(\mathrm{T}_{\mathrm{i}}\right)$, this allows building a unique $\left|E^{*}\right|$ curve $\left(\log \left(\left|E^{*}\right|\right), \log (\mathrm{f})\right)$ by expressing the test results at an arbitrarily chosen reference temperature $\left(\mathrm{T}_{\text {ref }}\right)$. Applying the TTSP results in a shifting procedure of the $\left|E^{*}\right|$ isotherm points alongside the frequency axis to their equivalent frequency value:

$\mathrm{f}_{e q}=\mathrm{f}_{i} \frac{f\left(T_{i}\right)}{f\left(T_{r e f}\right)}=\mathrm{f}_{i} \times a_{t}\left(T_{i}, T_{r e f}\right)$

Equation 7 considers the shifting function as a shift factor $\mathrm{a}_{\mathrm{T}}$ that depends on the test temperature and the chosen reference temperature. In this paper, the evolution of the shift factor is fitted by the Williams, Landel and Ferry (WLF) equation ${ }^{19}$ :

$\log \left(a_{T}\right)=\frac{-C_{1}\left(T-T_{r e f}\right)}{C_{2}+T-T_{r e f}}$

Where $\mathrm{C} 1$ and $\mathrm{C} 2$ are the constants of the WLF equation. Validating the TTSP for bituminous materials requires the existence of a unique line of the complex modulus test results when plotted in the Cole-Cole and Black spaces. These are presented in section 6 of this paper.

\section{Tested Materials}

The gap-graded studied mixture, named GB5 ${ }^{\circledR}$, was developed at the Centre for Studies and Research of the French road contractor EIFFAGE Travaux Publics. It is characterized by an optimized aggregate packing combined with the use of a SBS polymer modified binder (PMB). Two other French mixtures were tested: an "enrobé à module elevé" grade 2 (EME2) and a "grave bitume" grade 4 (GB4). These two materials are standardised French base-course mixtures (NF EN 13108-1) $)^{20}$.

The granular structure of the mixtures is composed of virgin basaltic aggregates, limestone filler and reclaimed asphalt pavement (RAP) aggregates. The characteristics of the three mixtures are presented in Table 1 and the aggregates grading curves are given in Figure 3. The EME2 and GB4 mixtures 
Table 1. Characteristics of the tested mixtures.

\begin{tabular}{lcccc}
\hline \multicolumn{1}{c}{ Mixture } & & $\begin{array}{c}\text { Bitumen type } \\
\text { (origin and grade) }\end{array}$ & $\begin{array}{c}\text { Binder content } \\
\text { [total mass \%] }\end{array}$ & $\begin{array}{c}\text { RAP content [total } \\
\text { mass \%] }\end{array}$ \\
\hline "Enrobé à Module Elevé" grade 2 & EME2 & BP Lavéra Pen 20/30 & 5.4 & 19.1 \\
"Grave Bitume" grade 4 & GB4 & BP Lavéra Pen 35/50 & 4.3 & 20 \\
"Grave Bitume" grade 5 & GB5 ${ }^{\circledR}$ & Biprène $^{\circledR}$ 41 R Pen 31 & 4.5 & 20 \\
\hline
\end{tabular}

were made using pure bitumen. The $\mathrm{GB} 5^{\circledR}$ contains modified bitumen called Biprène ${ }^{\circledR} 41 \mathrm{R}$, which was developed by the company EIFFAGE Travaux Publics. Its base bitumen is the same as the one used for the EME2 mixture and it contains $2.5 \%$ in weight of reticulated SBS polymer.

The specimens were obtained from $600 \times 400 \times 140 \mathrm{~mm}$ slabs made in the laboratory using a wheel compactor according to the European standard EN 12697-33 ${ }^{[21]}$. They were cored and sawed to obtain cylindrical samples of $64.4 \mathrm{~mm}$ in diameter and $160 \mathrm{~mm}$ height. The coring direction was parallel to the compactor's wheel movement direction. The voids content of each sample was obtained by means of the gamma-ray method (NF EN 12 697-7)22. Three samples where tested by material. Given the good repeatability of the tests, the results of only one test per material are presented of this paper. Table 2 presents the characterisation of the samples.

\section{Performed Complex Modulus Tests}

A hydraulic press is used to apply axial tension-compression sinusoidal loading to the cylindrical samples.

The axial strain amplitude $\left(\varepsilon_{1}\right)$ was maintained constant at $25 \mu \mathrm{m} / \mathrm{m}$. The considered axial strain used for monitoring the test was the average of the measurements from three $100 \mathrm{~mm}$ length extensometers disposed at $120^{\circ}$ form one another, as shown in Figure 4. A load cell was used to measure the force applied to the sample; the axial stress $(\sigma 1)$ was calculated. A temperature chamber was used to maintain the temperature conditions during the tests.

The used loading frequencies are shown in Figure 5. The samples where tested at each of those frequencies at seven different temperatures going from $-25^{\circ} \mathrm{C}$ to $45^{\circ} \mathrm{C}$. The used temperatures are presented on Figure 6 . For this paper, each temperature change is considered a test stage. The lowest used frequency, $0.001 \mathrm{~Hz}$, was only applied during the stages at $35^{\circ} \mathrm{C}$ and $45^{\circ} \mathrm{C}$ whit the aim of observing the behaviour of the material at very low equivalent frequencies. For the stage at $45^{\circ} \mathrm{C}$, the $10 \mathrm{~Hz}$ frequency was not tested. Less than 80 loading cycles were applied at each temperature-frequency couple. Previous studies demonstrate that this allows neglecting the heating problems due to viscous dissipation ${ }^{23,24}$. In order to verify the integrity of the sample throughout the entire test, three stages at $15{ }^{\circ} \mathrm{C}$ where made at the beginning; middle and end of the test.

\section{Modelling}

The 2S2P1D rheological model, developed in the Laboratory of Civil Engineering and Construction (LGCB) of the ENTPE/University of Lyon, was used for the presented simulation curves. It is a generalization of the Huet-Sayegh ${ }^{25}$ model and consists of 2 springs, 2 parabolic creep elements and 1 dashpot $^{13,14}$. The authors have found
Table 2. Characteristics of the presented samples.

\begin{tabular}{cccc}
\hline Sample & Mixture & $\begin{array}{c}\text { Voids content } \\
\text { [total mass \%] }\end{array}$ & $\begin{array}{c}\text { Max voids } \\
\text { content allowed } \\
\text { [total mass \%] }\end{array}$ \\
\hline$E N L 7142-6$ & EME2 & 5.0 & 6.0 \\
$E N L ~ 7144-3$ & GB4 & 6.5 & 8.0 \\
$E N L ~ 7212-3$ & $\mathrm{GB5}^{\circledR}$ & 4.7 & 6.0 \\
\hline
\end{tabular}

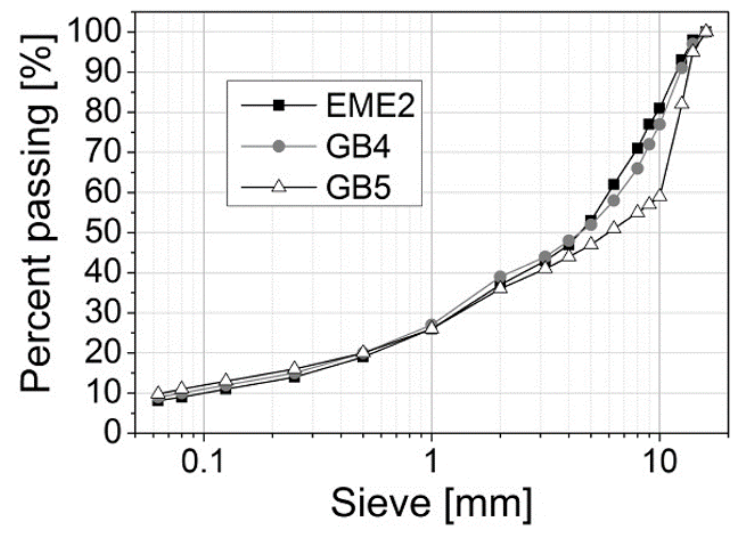

Figure 3. Grading curve of the tested mixtures.

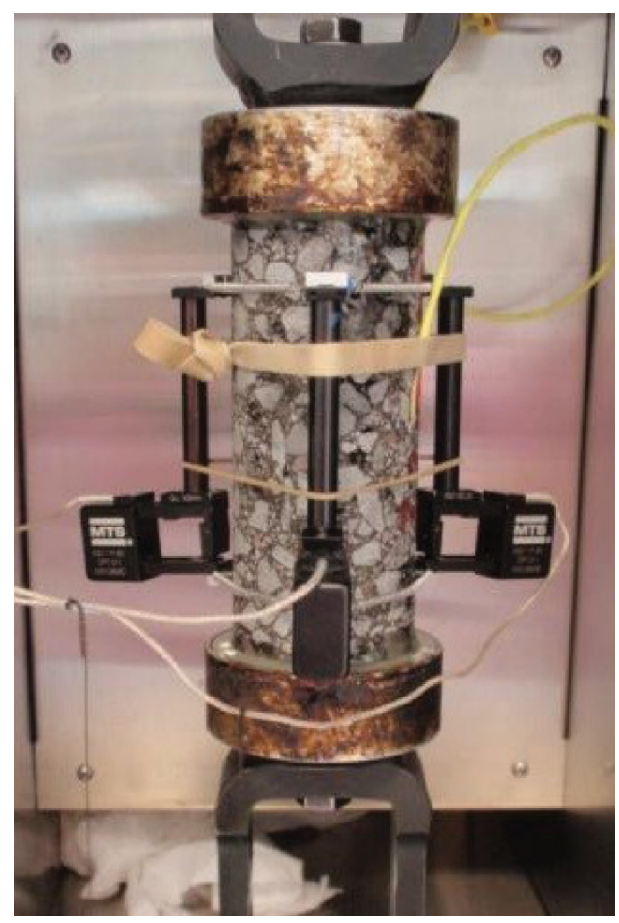

Figure 4. Instrumented sample in temperature chamber. 
the 2S2P1D model to suitably describe the linear viscoelastic behaviour of most bituminous materials over a wide range of frequencies and temperatures ${ }^{13,14,26,27}$. Equation 9 is the expression of $\mathrm{E}^{*}$ according to the $2 \mathrm{~S} 2 \mathrm{P} 1 \mathrm{D}$ model at a given temperature:

$$
E^{*}(\omega)=E_{00}+\frac{E_{0}-E_{00}}{1+\delta(j \omega \tau)^{-k}+(j \omega \tau)^{-h}+(j \omega \beta \tau)^{-1}}
$$

Where:

- $\omega$ is the pulsation, equal to $2 \pi \mathrm{f}$ with $\mathrm{f}$ the loading frequency. - $\mathrm{E}_{00}$ is the static modulus $(\omega \rightarrow 0)$. It is associated with the behaviour at low frequencies or high temperatures.

- $\mathrm{E}_{0}$ is the glassy modulus $(\omega \rightarrow \infty)$. It is associated with the behaviour high frequencies or low temperatures.

$-\delta$ is a calibration constant.

- $\mathrm{j}$ is the complex number $\left(\mathrm{j}^{2}=-1\right)$.

- $\tau$ is the characteristic time which depends on the temperature. It can be expressed as a function of the shift factor $\mathrm{a}_{\mathrm{T}}, \tau(\mathrm{T})=\mathrm{a}_{\mathrm{T}}(\mathrm{T})^{*} \tau_{0}$, where $\tau_{0}$ is determined at the reference temperature $\mathrm{T}_{\text {ref* }}$.

- $\mathrm{k}$ and $\mathrm{h}$ are constants defined such that $0<\mathrm{k}<\mathrm{h}<1$.

$-\beta$ is a constant that depends on the viscosity of the dashpot: $\eta=\left(E_{0}-E_{00}\right) \beta \tau$.

Only 7 parameters $\left(\mathrm{E}_{00}, \mathrm{E}_{0}, \delta, \beta, \tau, \mathrm{k}\right.$ and $\left.\mathrm{h}\right)$ are then required to completely characterise the LVE behaviour of

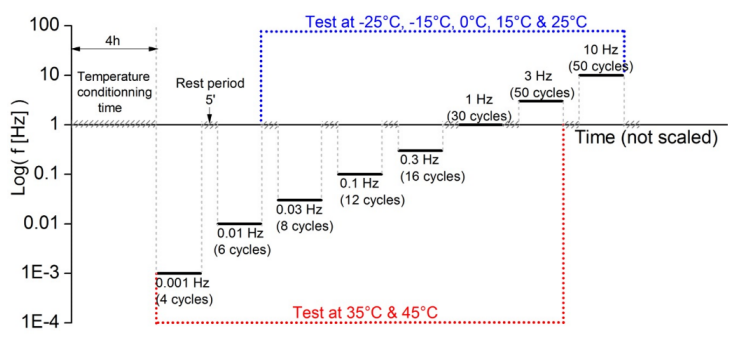

Figure 5. Tested frequencies for complex modulus test.

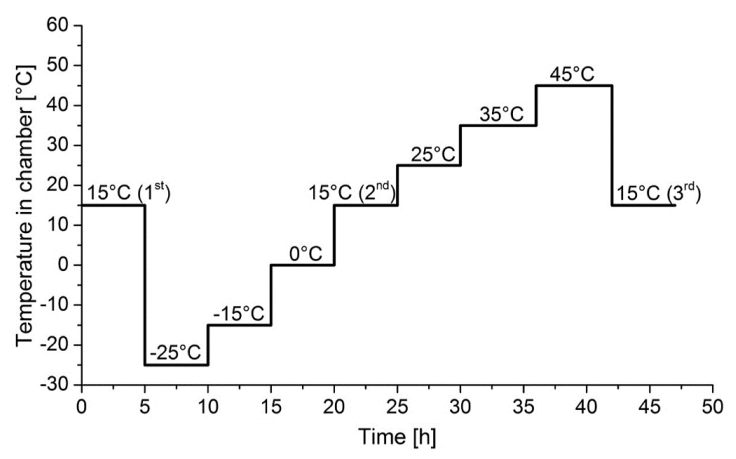

Figure 6. Applied temperatures for complex modulus test. a bituminous material. The WLF constants of Equation 8, calculated at the reference temperature, are also needed if the temperature effect is to be considered. Figure 7 presents the analogical representation of the 2S2P1D model and its parameters on a Cole-Cole diagram.

The values of the 2S2P1D model and of the WLF equation are shown in Table 3 for each of the studied materials; including the binder in the $\mathrm{GB} 5{ }^{\circledR}$ mixture. These constants are used in all the simulation curves presented in the next sections.

\section{Tests Results}

\subsection{Complex modulus}

Figure 8 presents the isotherm $\left|E^{*}\right|$ and $\varphi$ curves for a GB5 ${ }^{\circledR}$ sample. These express the evolution of the complex modulus and its phase angle for each test temperature at the tested loading frequencies.

The dependence of $\left|\mathrm{E}^{*}\right|$ and $\varphi$ with temperature is observed. The complex modulus norm increases with the decrease of temperature, while the opposite is observed for the phase angle.

Figure 8 also shows the influence of the loading frequency. An increase in the loading frequency implies an increase of $\left|E^{*}\right|$. As for the phase angle, it decreases with the increase of the frequency for all temperatures from $-25^{\circ} \mathrm{C}$ to $25^{\circ} \mathrm{C}$. For higher temperatures, this tendency seems to be reversed. A maximum phase angle value is obtained near $0.03 \mathrm{~Hz}$ at $34.4^{\circ} \mathrm{C}$.

For the two highest temperatures, phase angles measured at $0.001 \mathrm{~Hz}$ (dashed zone in Figure 8-right) do not fit with the other results. This is due to experimental limits of the test devices. For such a low frequency, the press is not able to impose a correct sinusoidal loading. The results at the lowest temperature tested $\left(-25^{\circ} \mathrm{C}\right)$ seem to indicate an asymptotic behaviour of $\left|\mathrm{E}^{*}\right|$ for very low temperatures.

Figure 9 presents the tests results for each of the studied mixtures in the Cole-Cole and Black diagrams. The Cole-Cole diagram expresses the relation between the real $\left(E_{1}\right)$ and imaginary $\left(\mathrm{E}_{2}\right)$ components of the material modulus, while the Black's diagram expresses the relation between the material stiffness and its viscosity. Simulation curves, also plotted in Figure 9, are obtained with the 2S2P1D model (cf. section 5). The used model constants are presented in Table 3 . The existence of a unique line in both diagrams validates the application of the TTSP for all of the mixtures. The 3 materials can then be considered as "thermorheologically simple", at least as a first (and good) approximation.

The lower maximum values of $\mathrm{E}_{2}$ and of the phase angle indicate a smaller viscous tendency of the $\mathrm{GB} 5^{\circledR}$ mixture respect to the two regular French mixtures. The GB4 mixture reaches a maximal phase angle close to $45^{\circ}$, which is more

Table 3. Calibration parameters for the $2 \mathrm{~S} 2 \mathrm{P} 1 \mathrm{D}$ model for the tested materials at $\mathrm{Tref}=14.9^{\circ} \mathrm{C}$.

\begin{tabular}{cccccccccc}
\hline Mixture & $\mathbf{E}_{\mathbf{0 0}}[\mathbf{M P a}]$ & $\mathbf{E}_{\mathbf{0}}[\mathbf{M P a}]$ & $\mathbf{k}$ & $\mathbf{h}$ & $\boldsymbol{\delta}$ & $\boldsymbol{\tau}_{\mathbf{0}}[\mathbf{s}]$ & $\boldsymbol{\beta}$ & $\mathbf{C 1}$ & $\mathbf{C 2}$ \\
\hline EME2 & 180 & 38700 & 0.162 & 0.490 & 2.25 & 0.16 & 300 & 29.05 & 191.3 \\
GB4 & 160 & 34800 & 0.163 & 0.530 & 1.95 & 0.3 & 100 & 24.85 & 161.5 \\
GB5 $^{\circledR}$ & 200 & 37600 & 0.132 & 0.430 & 2.15 & 0.3 & 800 & 29.15 & 191.3 \\
Biprène $^{\circledR} 41 \mathrm{R}$ & 0 & 2700 & 0.132 & 0.430 & 2.15 & $8 \cdot 10^{-7}$ & $1.8 \cdot 10^{6}$ & 24.49 & 183.0 \\
\hline
\end{tabular}



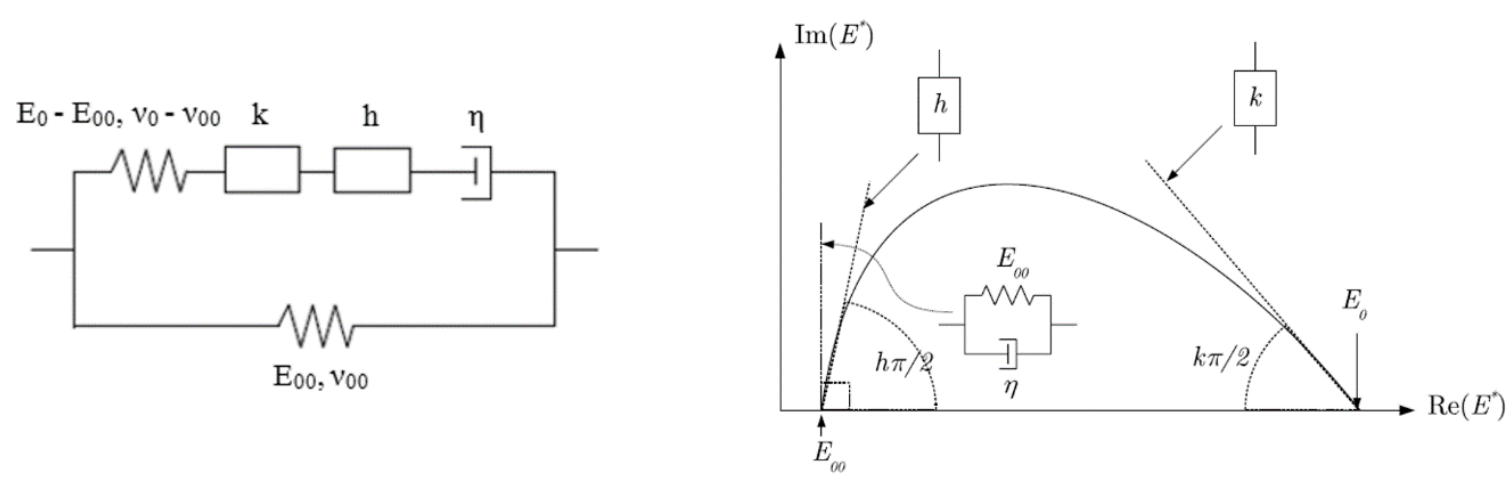

Figure 7. Analogical representation of the 2S2P1D Model (left) ${ }^{12}$ and graphical representation of the model's parameters on a Cole-Cole diagram (right).
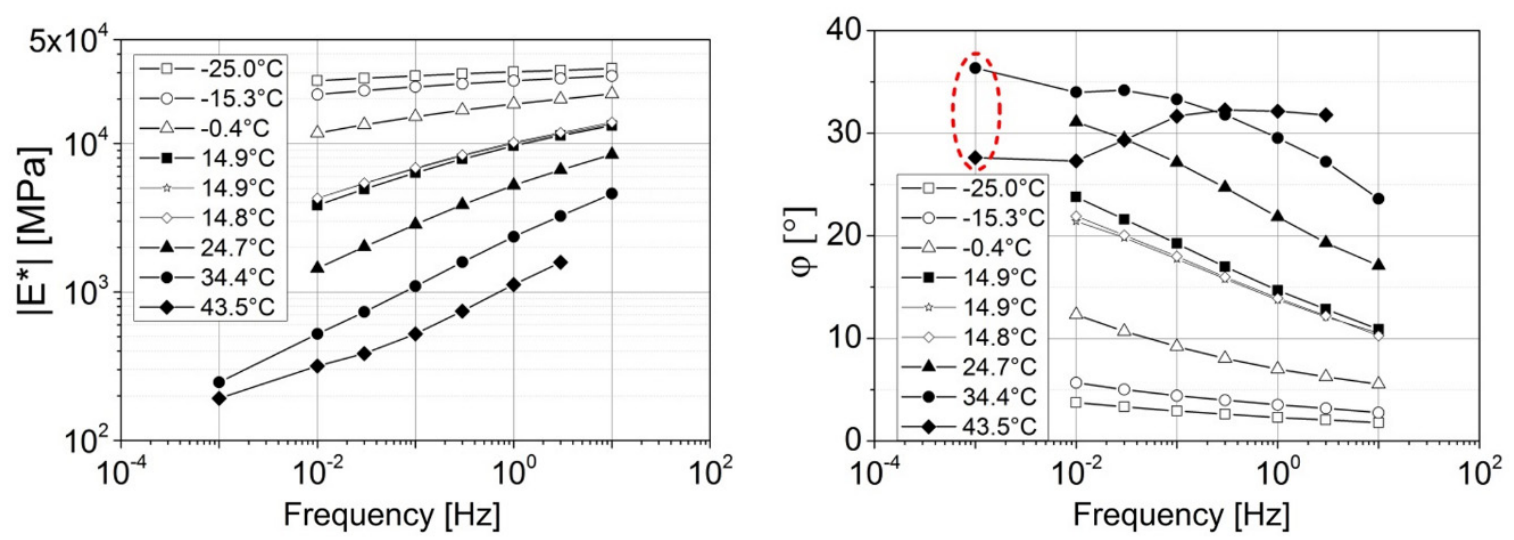

Figure 8. Experimental $\left|E^{*}\right|$ (left) and $\varphi$ (right) isotherm curves - GB5 ${ }^{\circledR}$ mixture - Dashed zone (right) corresponds to data at very low frequency and high temperature where system accuracy imply measurement error for phase angle.
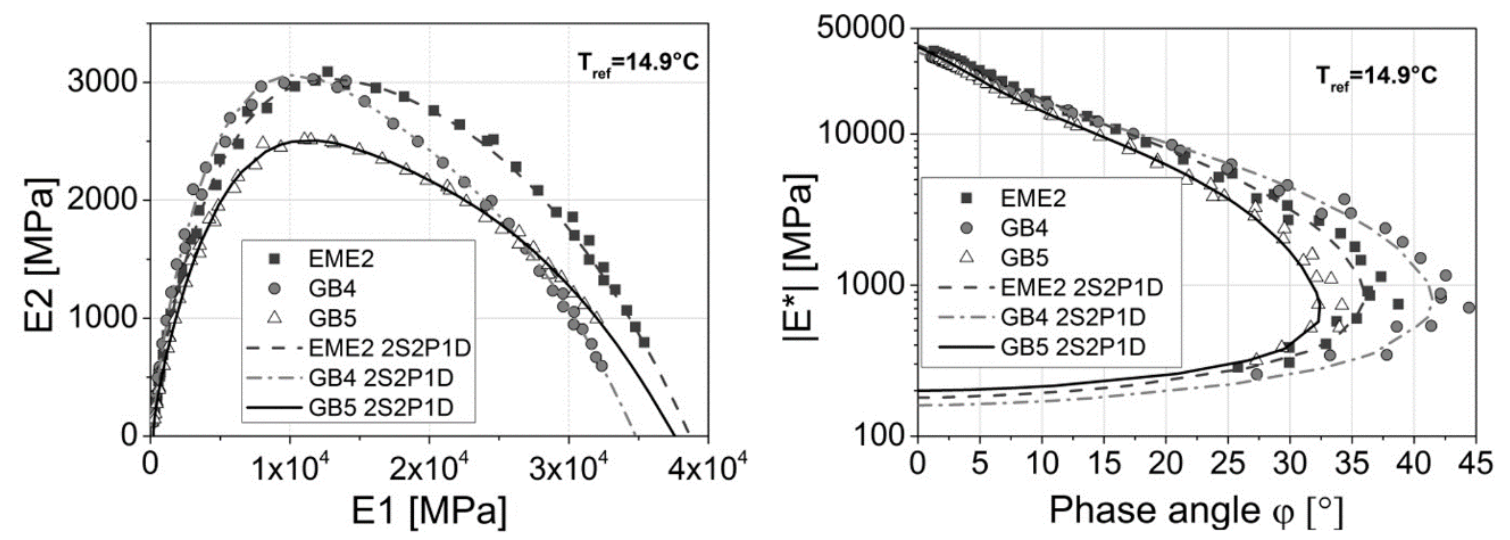

Figure 9. Cole-Cole (left) and Black (right) diagrams curves for each mixture.

than $10^{\circ}$ higher than the GB5 ${ }^{\circledR}$ 's. As for the EME2 mixture, there is a difference of $5^{\circ}$ between its maximal $\varphi$ at that of the GB5 ${ }^{\circledR}$ 's. The GB5 ${ }^{\circledR}$ glassy modulus $\mathrm{E}_{0}$ (the maximal $\left|E^{*}\right|$ value) is higher than the GB4's and very close to the EME2's. It is important to note that the latter is a mixture specially designed to have high complex modulus values. These results show the positive effect of the optimized granular packing which increases inter-granular contacts and gives high mechanical properties to the GB5 ${ }^{\circledR}$ mixture. Clear conclusions cannot be drawn for the static modulus
$\mathrm{E}_{00}$ due to the limitations of the experimental device at high temperatures and very low frequencies.

Master curves of $\left|E^{*}\right|$ and $\varphi$ are plotted in Figure 10 for the $\mathrm{GB} 5^{\circledR}$ mixture, and in Figure 11 for all three tested mixtures. Obtained shift factors (Equation 8), and their correspondent WLF fitting curves, are plotted in Figure 12. The chosen $\mathrm{T}_{\text {ref }}$ for this paper was $14.9^{\circ} \mathrm{C}$; then $\mathrm{a}_{\mathrm{T}}=1$ for the $14.9^{\circ} \mathrm{C}$ isotherms. The fitted shift factor $\mathrm{a}_{\mathrm{T}}$ associated to the $\mathrm{GB} 5{ }^{\circledR}$ mixture is very similar to the one of the EME2. It appears that SBS modification of the GB5 ${ }^{\circledR}$ binder does 
not affect the shift factor of the mixture. All fitting curves presented in Figures 10 and 11 are obtained from 2S2P1D model with constants given in Table 3 .

The low phase angle values at high frequencies/low temperatures and low frequencies/high temperatures is an evidence of the more elastic behavior $(\varphi \rightarrow 0)$ of bituminous mixtures at such extreme loading conditions. For high frequencies and low temperatures, the bitumen presents a very elastic behavior and it strongly influences the mixture behavior. For low frequencies/high temperatures the bitumen becomes very soft and the elastic aggregate structure dominates the mixture behavior. Bitumen polymer modification may, in part, explain the lower phase angle values developed at low frequencies by the $\mathrm{GB} 5^{\circledR}$ mixture and its frequency offset of its maximum value respect to the other two mixtures. The optimized granular interlocking allows the GB5 ${ }^{\circledR}$ mixture to maintain high modulus values at such extreme loading as the aggregates are in contact and able to undertake the efforts as the modified bitumen softens.

The simulation using the 2S2P1D model show a good fitting for both $\left|E^{*}\right|$ and $\varphi$. Nevertheless, the model hardly adjusts to the experimental values at very low frequencies, condition for which the experimental device also reaches its accuracy limit.

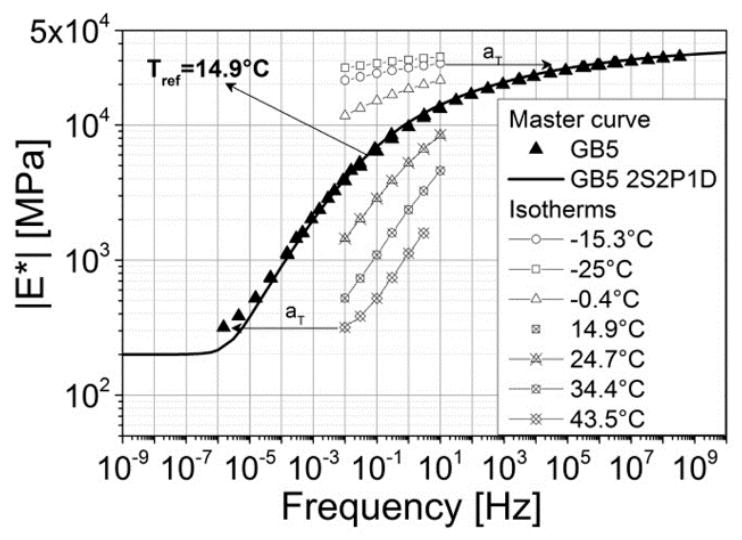

\subsection{Dissipated viscous energy}

During one loading cycle, dissipated energy due to viscous effects can be calculated for a unit volume using Equation 10:

$W=\pi \cdot \sin (\varphi) \cdot \sigma_{0} \cdot \varepsilon_{0}$

Experimental data presented in Figure 13 indicate the dissipated viscous energy obtained during the tests (at axial strain amplitude of $25 \mu \mathrm{m} / \mathrm{m}$ ) for the three tested materials. The curves represent the $2 \mathrm{~S} 2 \mathrm{P} 1 \mathrm{D}$ model simulation results for two types of loading conditions: constant axial strain amplitude of $\pm 25 \mu \mathrm{m} / \mathrm{m}$ and constant axial stress amplitude of $25 \mathrm{kPa}$. The strain amplitude corresponds to that used for the presented complex modulus tests. The chosen stress amplitude value allows attaining a similar energy dissipation maximal value as the one found under constant strain of $\pm 25 \mu \mathrm{m} / \mathrm{m}$

In real working conditions, a pavement structure is loaded under a combination of both strain and stress modes ${ }^{28,29}$. A clear difference on the energy dissipation curves is observed between the two piloting modes. It can be seen in Figure 13 that at constant stress amplitude, the maximum W value is reached at very low frequencies (circa $10^{-6} \mathrm{~Hz}$ ), while for a constant strain amplitude mode, the maximum $\mathrm{W}$ value is reached between $1 \mathrm{~Hz}$ and $10 \mathrm{~Hz}$. On either case,

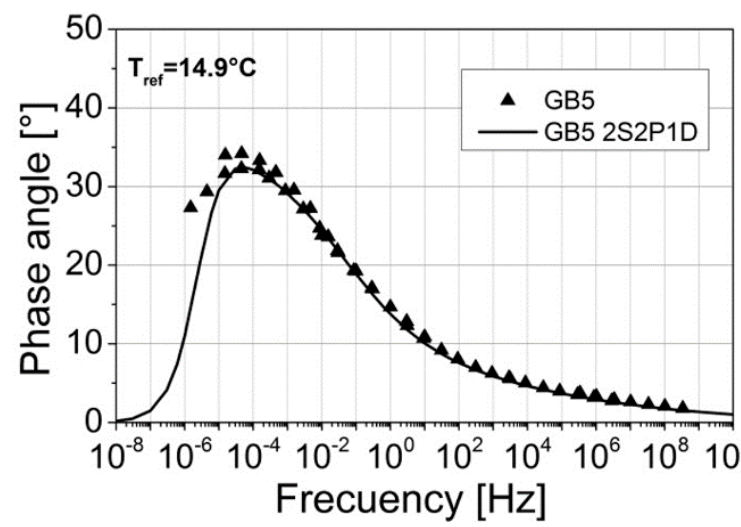

Figure 10. Master curves of the complex modulus (left) and phase angle (left) for GB5 ${ }^{\circledR}$.
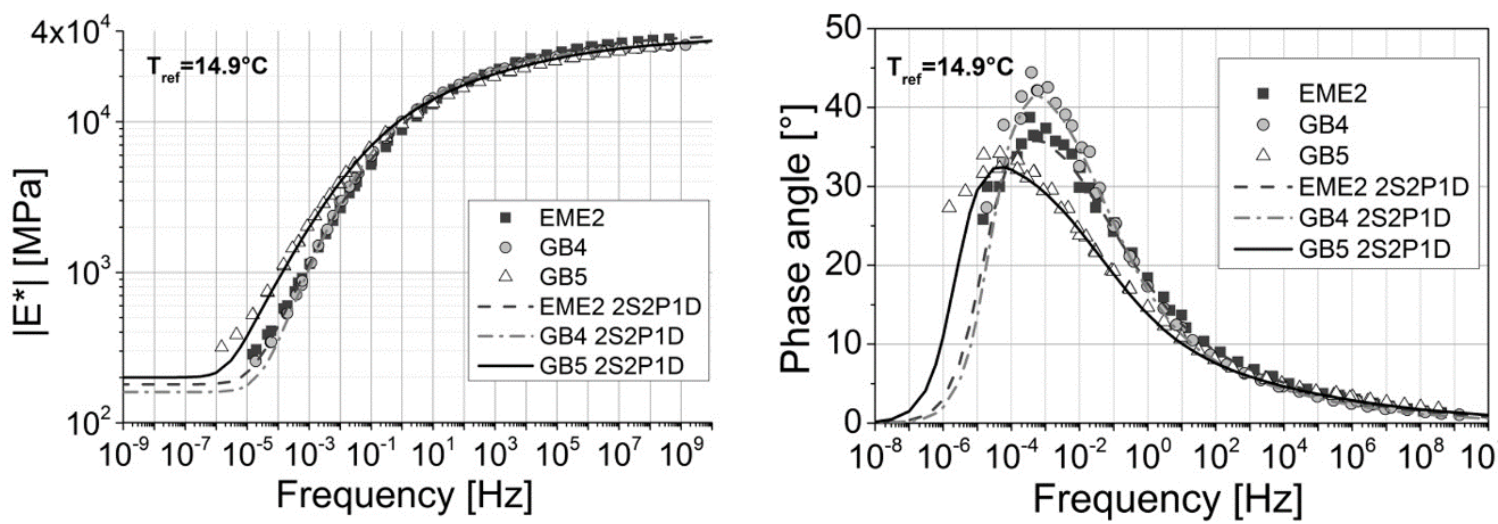

Figure 11. Master curves of the complex modulus (left) and phase angle (left). 
the $\mathrm{GB} 5{ }^{\circledR}$ mixture presents lower maximal dissipated energy than the tested regular base-course mixtures. Given that the usual exiting frequencies in road structures are lower than $100 \mathrm{~Hz}$, the GB5 ${ }^{\circledR}$ mixture is expected to dissipate less energy than the two other studied mixtures.

\section{Mixture Complex Modulus Prediction from Binder Properties}

The relation between bituminous mixture and binder complex moduli has been extensively studied ${ }^{13-16,26,27}$. Equation 11 presents the SHStS transformation (for Shift, Homotethy, Shift and time Shift) expression proposed by Di Benedetto and Olard ${ }^{13-16}$ that relates mixture and binder moduli:

$E_{\text {mix }}^{*}(\omega, T)=E_{00 \text { mix }}+\left[E_{\text {binder }}^{*}\left(10^{\alpha} \omega, T\right)-E_{00 \text { binder }}\right] \frac{E_{0 \text { mix }}-E_{00 \text { mix }}}{E_{0 \text { binder }}-E_{00 \text { binder }}}$

The proposed expression is independent of any rheological model. $\mathrm{E}_{00}$ and $\mathrm{E}_{0}$ (glassy modulus) correspond to the minimum and maximum asymptotic values of $\left|E^{*}\right|$ either for the mixture (" " ") or for the binder (" binder "), respectively. As mentioned on section $5, \mathrm{E}_{00}$ is the static modulus, obtained at very low loading frequencies (and/or very high temperature), and $\mathrm{E}_{0}$ is the glassy modulus, obtained at very high loading frequencies (and/or very low temperature). The exponent $\alpha$ is a constant that depends on the mixture.

The expression in Equation 11 corresponds to a transformation in the Cole-Cole diagram as explained on Figure 14. The points of the binder Cole-Cole curve are shifted of the $\mathrm{E}_{00 \text { binder }}$ value to the left along the $\mathrm{E}_{1}$ axis. An intermediate Cole-Cole curve is then built with homothetic transformation of the shifted binder points. The points of this intermediate curve are then shifted of the $\mathrm{E}_{00 \text { mix }}$ value to the right along the $\mathrm{E}_{1}$ axis in order to attain the Cole-Cole curve of the mixture. The points of the mixture Cole-Cole curve are associated to the same test temperature and to a frequency equal to $10^{-\alpha}$ times the frequency of the binder curve points.

Given the fact that binder $\mathrm{E}_{00}$ is either nil or much smaller than $\mathrm{E}_{0}$, Equation 11 can be simplified. Equation 12 takes into account this simplification as well as the hypothesis that the TTSP is verified for the binder.

$E_{\text {mix }}^{*}(\omega, T)=E_{00 \text { mix }}+\left[E_{\text {binder }}^{*}\left(10^{\alpha} \omega \alpha_{T \text { binder }}(T), T_{\text {ref }}\right)-E_{00 \text { binder }}\right] \frac{E_{0 \text { mix }}}{E_{0 \text { binder }}}$

Figure 15 shows the results of the predicting procedure for $\left|E^{*}\right|$ of the $\mathrm{GB}^{\circledR}{ }^{\circledR}$ mixture. The binder tests results and 2S2P1D simulations are also presented. The comparison between the predicted and the experimental values shows that the transformation method gives good results. The complex modulus of the binder was obtained using a Dynamic Shear Rheometer - DSR (NF EN 14770) ${ }^{30}$ at the Research Centre of EIFFAGE Travaux Publics. The tested binder was the virgin Biprène $^{\circledR} 41 \mathrm{R}$, so it does not take into account the RAP binder contribution. Figure 16 presents the experimental shift factor $\mathrm{a}_{\mathrm{T}}$ and the fitting curves obtained with the WLF equation (cf. section 2). The results confirm that the shift factor values for both binder and mixture are close to each other. The results presented in this section confirm the findings on the subject found in the literature ${ }^{31-39}$ as well as the powerful general approach developed at the ENTPE laboratory team in Lyon.

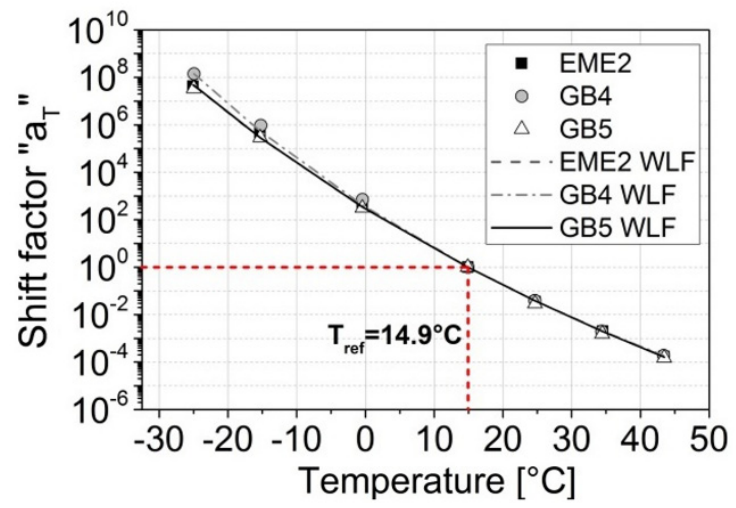

Figure 12. aT coefficient for each mixture.

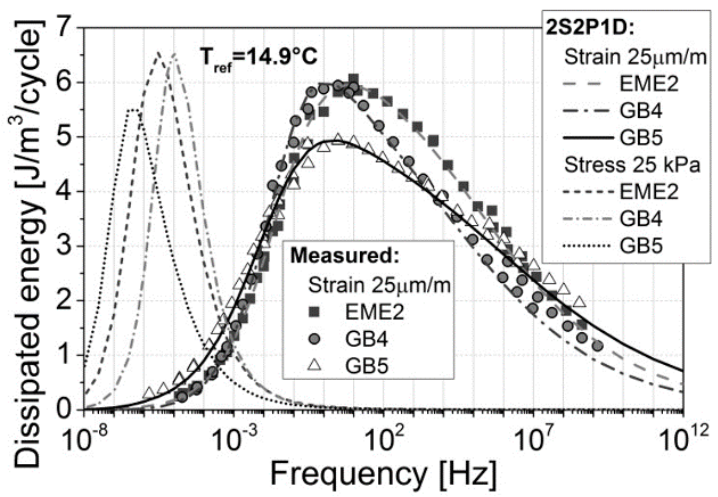

Figure 13. Viscous energy dissipation curves for each mixture Strain and stress control modes.

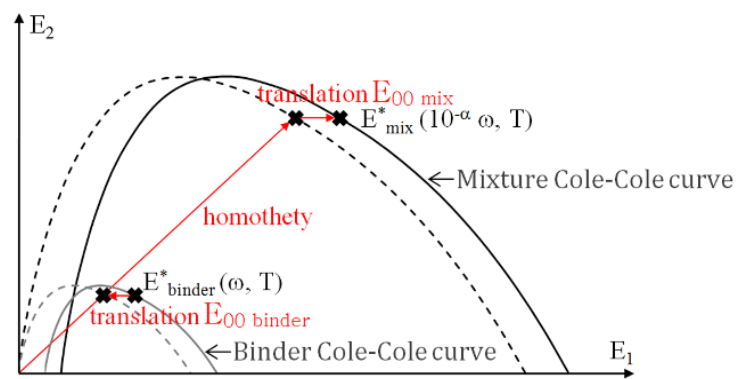

Figure 14. Geometrical transformation of the binder Cole-Cole diagram for prediction of the mixture modulus.

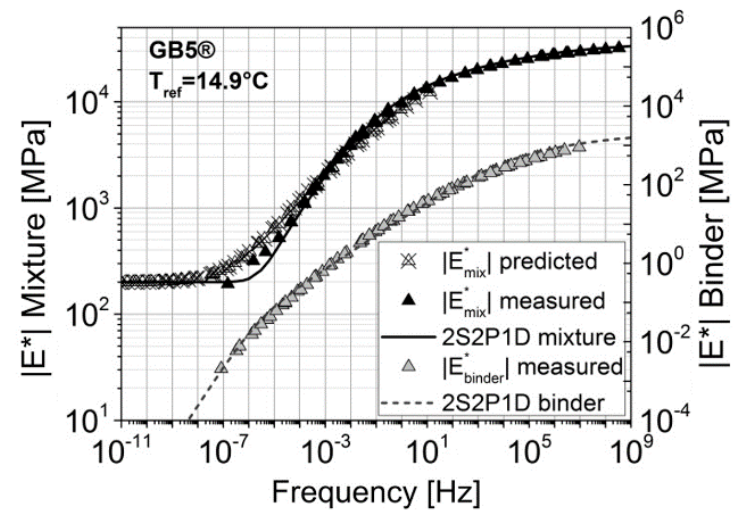

Figure 15. Measured master curves of $\left|E^{*}\right|$ of the $G B 5^{\circledR}$ mixture and its binder and predicted-from-binder $\left|\mathrm{E}^{*}\right|$ master curve of the GB5 ${ }^{\circledR}$ mixture. 


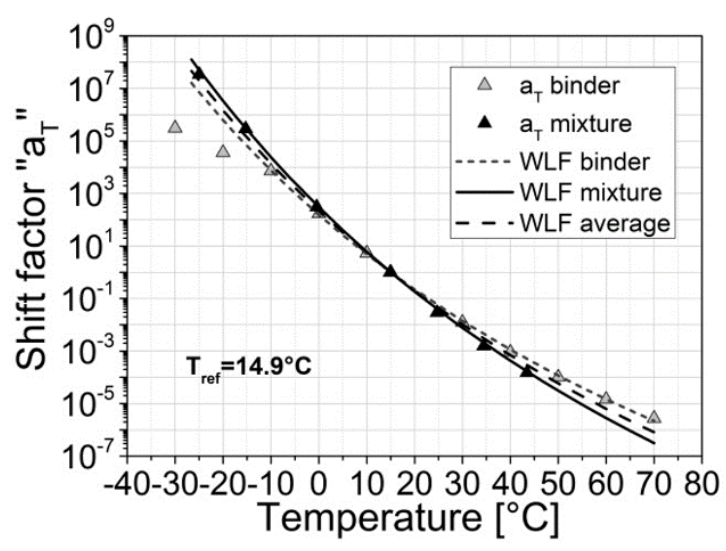

Figure 16. Shift factor aT for the GB $5^{\circledR}$ mixture and its binder and comparison with the WLF equation fit.

\section{Conclusions}

The linear thermo-viscoelastic behaviour of an innovative gap-graded base-course asphalt mixture, called GB5 ${ }^{\circledR}$, with polymer-modified bitumen is presented in this paper.

This was made by means of the complex modulus test on cylindrical samples under tension-compression loading. The GB5 ${ }^{\circledR}$ mixture was compared to two standardized and commonly used base-course French mixtures. It was found to have slightly different viscous behaviour than the other two tested mixtures. The GB5 ${ }^{\circledR}$ mixture presents a better performance at high temperatures and/or low frequencies,

\section{References}

1. Roque R, Huang S and Ruth B-E. Maximizing shear resistance of asphalt mixtures by proper selection of aggregate gradation. In: Proceedings of the 8th Int. Soc. for Asphalt Pavements; 1997; Seattle, USA. University of Washington; 1997. p. 249-268.

2. Kim S, Guarin A, Roque R and Birgisson B. Laboratory evaluation for rutting performance based on the DASR porosity of asphalt mixture. Road Materials and Pavement Design. 2008; 9(3):421-440. http://dx.doi.org/10.1080/14680629.2008.9690 126.

3. Cavalcante Lucena MC, De Aguiar Soares S and Barbosa Soares J. Characterization and thermal behavior of polymermodified asphalt. Materials Research-Iberoamerican Journal of Materials. 2004; 7(4):529-534.

4. Baaj H, Di Benedetto H and Chaverot P. Effect of binder characteristics on fatigue of asphalt pavement using an intrinsic damage approach. Road Materials and Pavement Design. 2005; 6(2):147-174. http://dx.doi.org/10.1080/14680629.2005.9690 003.

5. Santos Fernandes MR, Camargo Forte MM and Leite LFM. Rheological evaluation of polymer-modified asphalt binders. Materials Research-Iberoamerican Journal of Materials. 2008; 11(3):381-386

6. Dreessen S, Ponsardin M, Planche J-P, Dumont A-G and Pittet M. Durability study: field aging of conventional and cross-linked polymer modified bitumens. In: LJMU (Liverpool John Moores University) Conference. Liverpool; 2011.

7. Zeiada WA, Underwood BS, Pourshams T, Stempihar J and Kaloush KE. Comparison of conventional, polymer and rubber which may be of practical interest for road design. This was mainly attributed to the mixture's optimized gap gradation.

The studied GB5 ${ }^{\circledR}$ mixture reaches the performances of a high-performance mixture, EME type, while using a low quantity of softer bitumen and by optimizing the aggregates packing. The $\mathrm{GB} 5^{\circledR}$ mixture presents high modulus values associated with lower phase angle values compared to the EME mixture. This is most probably due to the optimized granular interlocking of the $\mathrm{GB}^{\circledR}{ }^{\circledR}$ mixture. Moreover, its mechanical performances were not compromised by the inclusion of RAP. Given the actual economic and ecological context, this represents a noticeable advantage over regular base-course mixtures used in France. Nevertheless, other properties must also be studied, such as its fatigue resistance, in order to validate its use as a base-course mixture.

The 2S2P1D model was used to simulate the LVE behaviour of the tested mixtures. The presented results of the simulation prove that the 2S2P1D model represents a powerful tool for the study of bituminous materials in the linear viscoelastic domain.

The SHStS transformation expression ${ }^{13-16}$ was used to establish the relation between the GB $5{ }^{\circledR}$ mixture and its binder complex moduli. This expression was found to accurately predict the complex modulus master curve of the mixture. It was observed that the shift factors $\mathrm{a}_{\mathrm{T}}$ of the polymer-modified binder and of the GB5 ${ }^{\circledR}$ mixture are nearly identical. The polymer modification of the $\mathrm{GB} 5^{\circledR}$ binder doesn't seem to alter the fact that the TTSP of the mixture directly depends on that of binder, which confirms results already found for other types of mixtures by the ENTPE team of Lyon ${ }^{13-16}$.

asphalt mixtures using viscoelastic continuum damage model. Road Materials and Pavement Design. 2014; 15(3):588-605. http://dx.doi.org/10.1080/14680629.2014.914965.

8. Airey GD and Rahimzadeh B. Combined bituminous binder and mixture linear rheological properties. Construction \& Building Materials. 2004; 18(7):535-548. http://dx.doi.org/10.1016/j. conbuildmat.2004.04.008.

9. Di Benedetto H, Partl MN, Francken L and De la Roche C. Stiffness testing for bituminous mixtures. Journal of Materials and Structures. 2001; 34(2):66-70. http://dx.doi.org/10.1007/ BF02481553.

10. Corte F and Di Benedetto H. Matériaux routiers bitumineux 2: constitution et propriétés thermomécaniques des mélanges. Lavoisier; 2004.

11. Di Benedetto H. Nouvelle approche du comportement des enrobés bitumineux: résultats expérimentaux et formulation rhéologique. In: Proceedings of the Fourth RILEM symposium: Mechanical tests for bituminous mixes, characterization, design and quality control; 1990; Budapest, Hungry. 1990. In French.

12. Nguyen H-M, Pouget S, Di Benedetto H and Sauzéat C. Generalization of the time-temperature superposition principle for bituminous mixtures: experimentation and modelling. European Journal of Environmental and Civil Engineering. 2009; 13(9):1095-1107. http://dx.doi.org/10.1080/19648189 .2009 .9693176 .

13. Di Benedetto H, Delaporte B and Sauzéat C. Three-dimensionnal linear behavior of bitu-minous materials: experiments and modelling. International Journal of Geomechanics. 2007; 7(2):149-157. http://dx.doi.org/10.1061/(ASCE)1532-3641(2007)7:2(149). 
14. Di Benedetto H, Olard F, Sauzéat C and Delaporte B. Linear viscoelastic behaviour of bituminous materials: From binders to mixes. International Journal of Road Materials and Pavement Design. 2004; 5(suppl 1):163-202. http://dx.doi.org/10.1080/1 4680629.2004.9689992.

15. Olard F. Comportement thermomécanique des enrobés bitumineux à bases temperatures: relations entre les propriétés des liants et des enrobés (Dissertation). Ecole Doctorale des Sciences pour l'Ingénieur de Lyon; 2003. In French.

16. Olard F, Di Benedetto H, Eckmann B and Triquigneaux J-P. Linear viscoelastic properties of bituminous binders and mixtures at low and intermediate temperatures. International Journal of Road Materials and Pavement Design. 2003; 4(1):77-107. http://dx.doi.org/10.1080/14680629.2003.9689941.

17. Pouget S, Sauzéat C, Di Benedetto H, Olard F. From the behaviour of constituent materials to the calculation and design of orthotropic steel bridge structures. Road Materials and Pavement Design. 2010; 11(SI EATA):111-144.

18. Corte F and Di Benedetto H. Matériaux routiers bitumineux 1: description et propriétés des constituants. Lavoisier; 2004.

19. Ferry J-D. Viscoelastic properties of polymers. John \& Sons; 1987.

20. Association Française de Normalisation - AFNOR. NF EN 13108-1: spécifications des matériaux Partie 1: Enrobés bitumineux. Paris; 2007.

21. Association Française de Normalisation - AFNOR. NF EN 12697-33+A1: mélange bitumineux - Méthodes d'essai pour mélange hydrocarboné à chaud - Partie 33 : confection d'éprouvettes au compacteur de plaque. Paris; 2007.

22. Association Française de Normalisation - AFNOR. NF EN 12 697-7: Mélanges bitumineux: méthodes d'essai pour mélange hydrocarboné à chaud - Méthodes d'essai pour mélange hydrocarboné à chaud. Partie 7: détermination de la masse volumique apparente des éprouvettes bitumineuses par les rayons gamma. Paris; 2003.

23. Nguyen Q-T, Di Benedetto H and Sauzéat C. Determination of thermal properties of asphalt mixtures as another output from cyclic tension-compression test. Road Materials and Pavement Design. 2012; 13(1):85-103. http://dx.doi.org/10.1080/14680 629.2011.644082.

24. Di Benedetto H, Nguyen Q-T and Sauzéat C. Nonlinearity, heating, fatigue and thixotropy during cyclic loading of asphalt Mixtures. Road Materials and Pavement Design. 2011; 12(1):129-158. http://dx.doi.org/10.1080/14680629.2011.969 0356.

25. Huet C. Etude par une méthode d'impédance du comportement viscoélastique des matériaux hydrocarbonés. Faculté des Sciences de 1’Université de Paris; 1963. p. 69.

26. Di Benedetto H, Olard F, Sauzéat C and Delaporte B. Linear viscoelastic behavior of bituminous materials: from binders to mixes. Road Materials and Pavement Design. 2004; 5(Suppl):163-202. http://dx.doi.org/10.1080/14680629.2004 .9689992 .

27. Olard F, Di Benedetto H, Dony A and Vaniscote J-C. Properties of bituminous mixtures at low temperatures and relations with binder characteristics. Materials and Structures. 2005; 38(1):121-126. http://dx.doi.org/10.1007/BF02480584.
28. Pouget S, Sauzéat C, Di Benedetto H and Olard F. Viscous energy dissipation in asphalt pavement structures and implication for vehicle fuel consumption. Journal of Materials in Civil Engineering. 2012; 24(5):568-576. http://dx.doi.org/10.1061/ (ASCE)MT.1943-5533.0000414.

29. Pouget S, Sauzéat C, Di Benedetto H and Olard F. Calculation of viscous energy dissipation in asphalt pavements. Baltic Journal of Road and Bridge Engineering. 2014; 9(2):123-130. http://dx.doi.org/10.3846/bjrbe.2014.16.

30. Association Française de Normalisation - AFNOR. NF EN 14770: Bitumes et liants bitumineux: détermination du module complexe en cisaillement et de l'angle de phase: rhéomètre à cisaillement dynamique (DSR). Paris; 2012.

31. Delaporte B, Di Benedetto H, Chaverot P and Gauthier G. Linear viscoelastic properties of bituminous materials including new products made with ultrafine particles. Road Materials and Pavement Design. 2009; 10(1):7-38. http://dx.doi.org/10.108 0/14680629.2009.9690180.

32. Di Benedetto H, Sauzéat C and Sohm J. Stiffness of bituminous mixtures using ultrasonic waves propagation. Road Materials and Pavement Design. 2009; 10(4):789-814. http://dx.doi.org $/ 10.1080 / 14680629.2009 .9690227$.

33. Tiouajni S, Di Benedetto H, Sauzéat $\mathrm{C}$ and Pouget $\mathrm{S}$. Approximation of linear viscoelastic model by generalized Kelvin Voigt or generalized Maxwell Models: Application to bituminous materials in the 3 dimensional case. Road Materials and Pavement Design. 2011; 4(12):897-930.

34. Pouget S, Sauzéat C, Di Benedetto H and Olard F. Modeling of viscous bituminous wearing course materials on orthotropic steel deck. Materials and Structures. 2012; 45(7):1115-1125. http://dx.doi.org/10.1617/s11527-011-9820-z.

35. Di Benedetto H, Delaporte B and Sauzéat C. Three-dimensional linear behavior of bituminous materials: experiments and modeling. International Journal of Geomechanics. 2007; 7(2):149-157. http://dx.doi.org/10.1061/(ASCE)1532-3641(2007)7:2(149).

36. Mangiafico S, Di Benedetto H, Sauzéat C, Olard F, Pouget S, Planque L. Influence of RAP content on complex modulus of asphalt binder blends and corresponding mixes: experimental results and modeling. Road Materials \& Pavement Design. 2013; 14(S1):132-148.

37. Tapsoba N, Sauzéat C, Di Benedetto H, Baaj H and Ech M. Behavior of asphalt mixtures containing and reclaimed asphalt pavement and shingles. Road Materials and Pavement Design. 2014; 15(2):330-347. http://dx.doi.org/10.1080/14680629.201 3.871091 .

38. Mangiafico S, Di Benedetto H, Sauzéat C, Olard F, Pouget S and Planque L. New method to obtain viscoelastic properties of bitumen blends from pure and and reclaimed asphalt pavement binder constituents. Road Materials and Pavement Design. 2014; 15(2):312-329. http://dx.doi.org/10.1080/14680629.20 13.870639 .

39. Moon KH, Falcetto AC and Marasteanu MO. Rheological modelling of asphalt materials properties at low temperatures: from time domain to frequency domain. Road Materials and Pavement Design. 2013; 14(4):810-830. http://dx.doi.org/10. 1080/14680629.2013.817351. 